\title{
UNRECOGNISED FRACTURES AND DISLOCATIONS OF THE CERVICAL SPINE
}

\author{
By A. T. ScHER, M.B., Ch.B., D.M.R.D. \\ Department of Radiology, and Spinal Cord Injuries Centre, \\ Conradie Hospital, Cape Town, South Africa
}

\begin{abstract}
Failure to diagnose a fracture of the spine may lead to spinal cord damage due to incorrect handling of the patient. The three most common causes of failure to radiologically diagnose a fracture of the cervical spine after injury are: (I) Inadequate demonstration of the entire cervical spine on the lateral view; (2) Failure to X-ray the cervical spine after head injury; (3) Incorrect interpretation of the radiological appearances. The relevant radiological features are discussed.
\end{abstract}

Key words: Cervical spine; Tetraplegia

\section{Introduction}

DiAGNOSIS of a fracture or dislocation of the cervical spine as result of injury is usually made radiologically. If the patient has no neurological deficit and a negative X-ray report, this should remove any suspicion of injury to the vertebral column. Should a fracture and/or dislocation be present and misinterpretation of radiographs made, the patient would be at considerable risk of the onset of avoidable tetraplegia. This could have serious medico-legal implications for the doctor as well as being catastrophic for the patient. Geisler (I966), reviewing a series of spinal cord injury patients, reported a 3 per cent incidence of delayed paralysis due to 'faulty' management.

Failure to demonstrate injuries of the spine is not always the fault of the radiologist. In the absence of obvious physical signs the clinician may overlook the possibility of spinal injury and fail to request X-ray examination. At hospitals in remote areas and without $\mathrm{X}$-ray facilities failure to diagnose spinal injury is understandable, but occasionally patients with undetected injuries of the cervical spine have been admitted to this Spinal Cord Injuries Centre, via the casualty and radiological departments of hospitals with adequate radiographic equipment and staff.

In our experience the causes of failure to diagnose injury to the cervical spine radiologically are:

I. Inadequate demonstration of the entire cervical spine, particularly the cervico-dorsal junction.

2. Failure to X-ray the cervical spine following head injury.

3. Incorrect interpretation of the radiological appearances.

\section{Discussion}

\section{Inadequate Demonstration of the Cervico-Dorsal function}

The cervico-dorsal junction is a difficult area to examine radiographically. Unfortunately a significant percentage of fractures and dislocations occur at this 
level. During the 3 years 1972-1974, of the 212 spinal cord injury patients admitted to our Unit, 34 per cent had sustained injury between the level of C6 and TI (Scher \& Vambeck, I977).

Determination of fractures and dislocations of the cervical spine is usually made on the lateral view. Antero-posterior and oblique views are of value in confirming diagnosis but the lateral radiograph is of paramount importance and, unless the vertebrae are specifically counted non-visualisation of $\mathrm{C}_{7}$ could be easily overlooked.

Patients who sustain severe trauma causing spinal column injury are X-rayed in the supine position. In this position the patient's shoulders tend to obscure the lower cervical spine on the lateral radiograph. Muscular spasm, fractures of the ribs or upper limbs and associated pain, prevents the patient from relaxing and may further increase the height of the shoulders. Of 45 acute cervical spinal cord injury patients, studied sequentially, $\mathrm{C}_{7}$ was demonstrated in only 19 cases when using the standard horizontal beam lateral view (Scher \& Vambeck, I977).

We have found that the 'Pulled' lateral view will provide satisfactory visualisation of the lower cervical spine in most cases. When this is unsuccessful the 'Flying Angel' (Swimmers) view will usually demonstrate the C6/TI area. These views are technically simple and do not require potentially hazardous movement of the patient's head or neck.

\section{'Pulled' Lateral View}

The pulled horizontal beam lateral view as described by Lodge and Higginbottom (I966) is used in our unit, except that we prefer the patient's arms to be held above the elbows and pulled across the chest and downwards by the assistants. This method clears the shoulders away from the lower cervical spine more satisfactorily. Fig. I, A and B illustrate the value of this view.

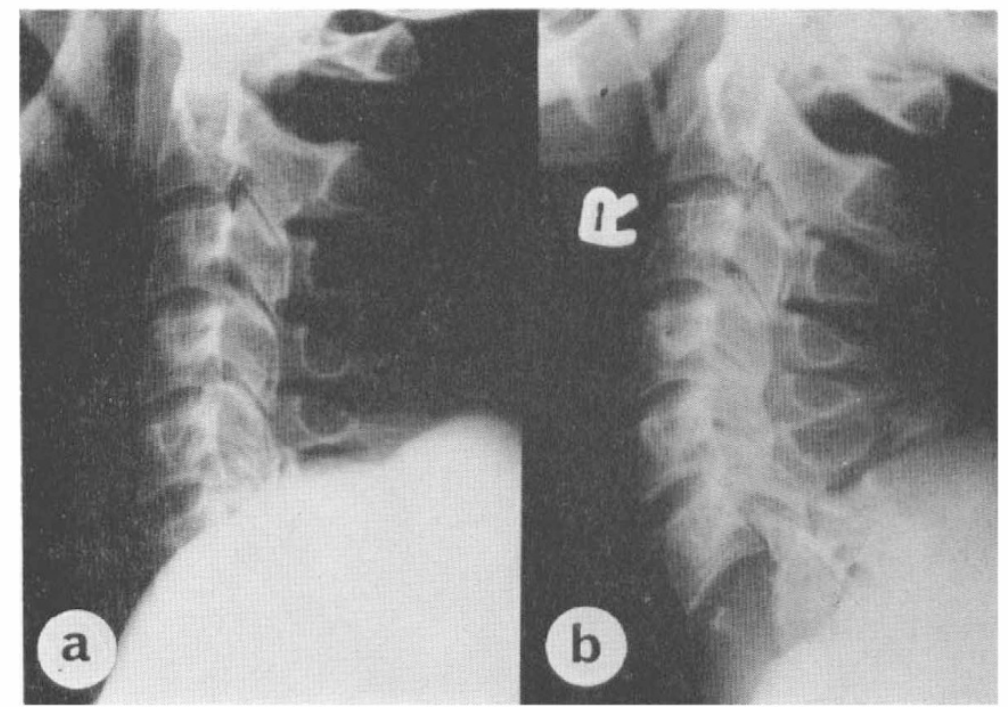

FIG. I

(A) Standard supine lateral view. $\mathrm{C}_{7}$ is not demonstrated. (B) 'Pulled' lateral view. $\mathrm{C}_{7}$ is well demonstrated and the fractured vertebral body clearly seen. 
'Flying Angel' Views

In the supine technique, one arm is raised above the head with the cassette placed against the lateral aspect of the shoulder. The opposite shoulder is depressed by pulling the arm downwards and the horizontal beam centred on the acromion. In the few cases for which this may prove unsatisfactory the 'Modified Flying Angel' may be used. For this view the patient is positioned as above and the casette placed against the lateral aspect of the chest, the top being level with the head of the humerus. The horizontal beam is centred through the spinous process of $\mathrm{C}_{7}$ at an angle of $45^{\circ}$ towards the feet (Scher \& Vambeck, I977).

\section{Failure to X-ray the Cervical Spine after Head Injury}

The association of cervical spine and head injury is often overlooked (Scher I977). The cervical spine may be injured by a direct blow to the neck but more often the injury is caused by indirect forces as a result of trauma to the head or face. In an assessment of 50 patients with cervical spine injuries, Shrago (1973) found that 35 per cent showed evidence of concurrent head trauma.

To take skull radiographs of a patient who has sustained head injury is common practice but unless there are clinical signs of neck injury it is unlikely that X-ray examination of the cervical spine will be requested. However, these signs are not always evident, particularly in an unconscious patient.

Upper cervical spine injuries are those most likely to occur in conjunction with trauma to the head. The atlas and axis with the occipital condyles act as a unit, functionally, embryologically and anatomically distinct from the lower cervical spine. Fractures of the upper cervical spine often occur without neurological deficit as the widest diameter of the cervical spinal canal is at the $\mathrm{CI}_{1} / \mathrm{C}_{2}$ level, which is also the point of maximum canal-to-cord-area ratio.

To perform the standard series of cervical spine radiographs on every patient who has sustained head or facial injury is impractical and inadvisable, as the undue manipulation of the head and neck required to obtain these views may precipitate spinal cord damage. It is therefore suggested that a supine horizontal beam lateral view of the cervical spine is obtained on all patients with decreased level of consciousness after head injury. If the lower cervical spine is not visualised on this view a 'Pulled' lateral, as described above, should be taken.

\section{Interpretation of Radiological Appearances}

\section{Alteration of the Normal Lordotic Curve}

Straightening of the normal cervical lordotic curve is often considered to be indicative of muscular spasm. In fact this feature is of little significance. Weir (I975) found a straight spine in 20 per cent of normal patients and, by depressing the chin I inch, the figure increased to 70 per cent. What is much more significant is a sharp alteration in contour, localised to one disc space (Scher, 1977). An acute lordotic angulation may indicate hyperextension injury with ligamentous damage, and an acute kyphotic deformity is indicative of flexion injury as shown in Fig. 2.

\section{Widening of the Prevertebral Soft Tissue}

Haemorrhage into the prevertebral soft tissue may cause it to widen sufficiently to be radiographically demonstrated. The soft tissue density should be 


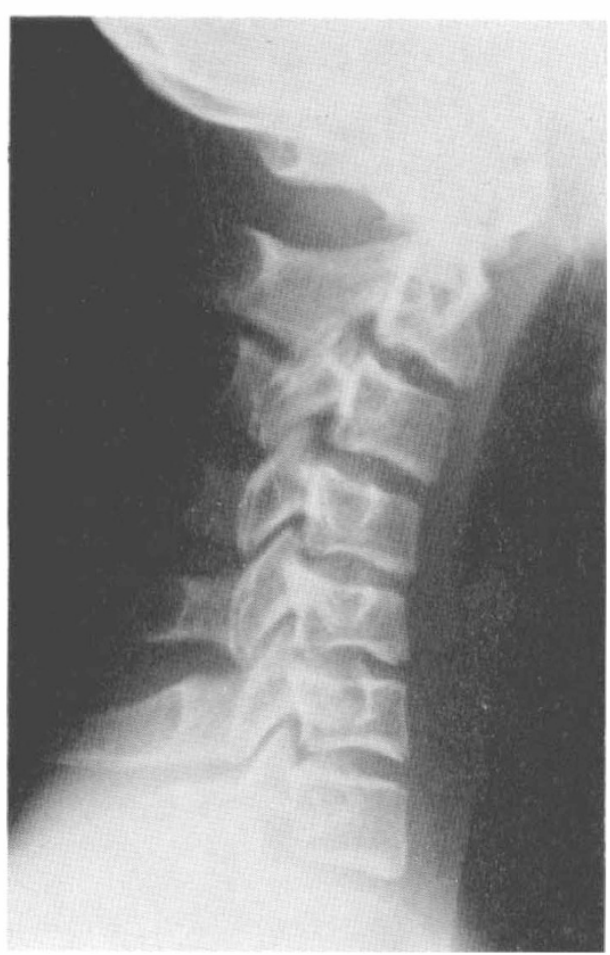

FIG. 2

Acute kyphotic angulation at the $\mathrm{C}_{3} / \mathrm{C}_{4}$ level indicating ligamentous damage after a flexion injury.

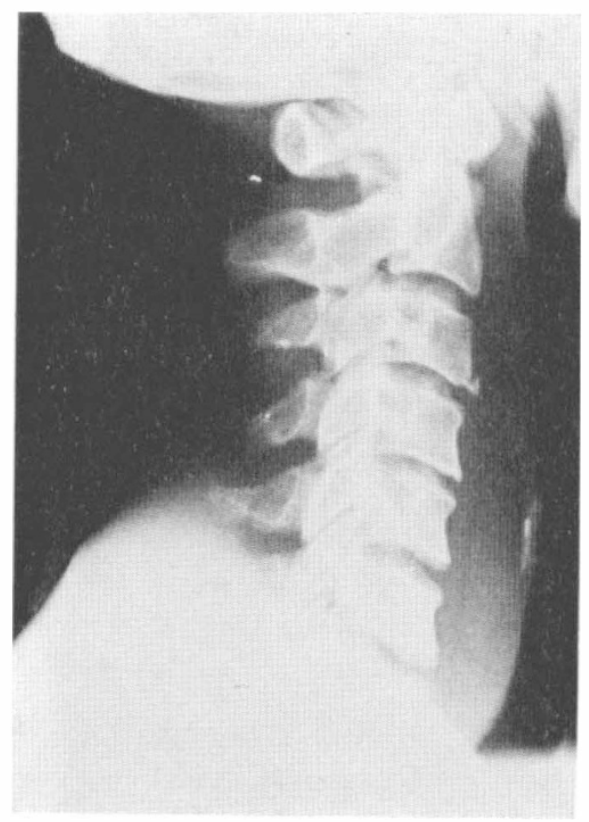

FIG. 3

Widening of the prevertebral soft tissue due to haemorrhage, with small avulsion fracture of the $\mathrm{C}_{3}$ vertebral body indicating hyperextension injury. 
measured at the antero-inferior border of the third cervical vertebral body. At this level the prevertebral soft tissues are clearly outlined by air in the hypopharynx. If the measurement is $5 \mathrm{~mm}$, or more, it is an indication of cervical spine injury and a careful search for fractures should be made Weir (1975). Fig. 3 demonstrates this sign in association with a fracture.

\section{Divergence of Spinous Processes}

The long axes of the spinous processes are related so that lines drawn through them will converge at a central point posterior to the neck. If the interspinal ligaments have been damaged by flexion injury then divergence of the spinous processes at the level of injury will be noted (Bailey, 1974; Scher, 1978).

\section{Posterior Displacement of a Vertebral Body}

The posterior aspects of the vertebral bodies are normally in smooth and unbroken alignment. If a line is drawn on the lateral radiograph connecting the posterior edges of the vertebral bodies a break in the alignment is suggestive of trauma, posterior displacement being indicative of hyperextension injury.

\section{Other Signs of Hyperextension Injury}

The radiological signs of cervical hyperextension injuries are more subtle than those of flexion injury and one or more of the following features may be present:

I. A small avulsion fracture of the anterior surface of a vertebral body. This fragment of bone is avulsed by the forced hyperextension of the anterior longitudinal ligament, as shown in Fig. 3.

2. A fracture of a spinous process unassociated with a vertebral body fracture. This is due to compression of the spinous processes by forced hyperextension.

3. Slight widening of an intervertebral disc space due to tearing of the disc on hyperextension.

The above injuries may appear relatively unimportant, but they should alert the radiologist to the fact that the patient has sustained hyperextension injury. These are potentially unstable injuries, particularly if the anterior longitudinal ligament and the intervertebral disc have been torn. Care in the handling of these patients is necessary to prevent further damage to the spinal cord.

Two other radiological features reported as being of value are displacement of the prevertebral fat stripe (Whalen and Woodruff, I970), and the 'Lucent Cleft' (Raymond et al., 1972). However, these signs have not proved to be of value in our experience (Scher, I976).

\section{Conclusion}

The ever-increasing number of acute cervical spinal cord injuries, particularly those due to motor vehicle accidents, make correct diagnosis of spinal injury essential. Fortunately fractures of the cervical spine are often unassociated with neurological deficit but incorrect handling of a patient with an unrecognised unstable fracture may precipitate irreversible paralysis. Therefore radiographic examination providing visualisation of the entire cervical spine on the lateral view is essential after injury to the head or neck. 


\section{RÉSUMÉ}

Une fracture de la colonne vertébrale, que l'on manque de diagnostiquer, peut conduire à des troubles du cordon médullaire, dus à une mauvaise manipulation du patient. Les trois causes les plus connues dans l'inobservation radiologique d'un diagnostique de fracture de la colonne cervicale à la suite d'un accident sont les suivantes. I. Vue latérale de la colonne vertébrale entiére non représentée. 2. Colonne vertébrale non radiographée à la suite d'une blessure cranienne. 3. Interprétation incorrecte du tracé radiographique. Les aspects radiologique appropriés sont discutés.

\section{ZUSAMMENFASSUNG}

Fehldiagnose einer Rückgratfraktur könnte weitere Verletzung der Wirbelsäule verursachen durch falsches anfassen des Patienten. Die drei häufigsten Ursachen die zu einer falschen Röntgendiagnose der Halswirbelsäule Führen, sind:

I. Unklares Bild der Halswirbelsäule in seitlicher Sicht.

2. Das vernachlassigen einer Halswirbelröntgenaufnahme nach Kopfverletzungen.

3. Falsche Interpretation der Röntgenaufnahme.

Die zutreffednen radiologischen Besonderheiten werden besprochen.

\section{REFERENCES}

BaIley, R. W. (1974). The Cervical Spine, p. 127. Lea \& Febiger, Philadelphia.

Geisler, W. C., WYNne-Jones, M. \& Jousse, A. T. (I966). Early management of the patient with trauma to the spinal cord. Med. Serv. F. Canada., 23 512-522.

Lodge, T. \& Higginbottom, E. (I966). Fractures and dislocations of the cervical spine. $X$-ray Focus., 7, I-6.

Reymond, D. R., Wheeler, P. S., Perovic, M. \& Block, B. (1972). The Lucent cleft, a new radiographic sign of cervical disc injury or disease. Clin. Radiol., 23, I88-192.

SCHER, A. T. (1976). Cervical spinal cord injury without evidence of fracture or dislocation. S. Afr. Med. F., 50, 962-965.

SCHER, A. T. (1977). A plea for routine radiographic examination of the cervical spine after head injury. S. Afr. Med. F., 5I, 885 .

SCHER, A. T. (1978). Ligamentous injury of the cervical spine-Two radiological signs. S. Afr. Med. F., 53, 802.

SCHER, A. T. \& VAMBECK, V. (1977). An approach to the radiology of the cervico-dorsal junction. Clin. Radiol., 28, 243.

ShrAGo, G. G. (1973). Cervical spine injuries: Association with head trauma. Radiology, II8, 670 .

WeIR, D. C. (1975). Roentgenographic signs of cervical injury. Clin. Orthop. and Related Research, No. 109, 9. 